\title{
Taxes on Severance Pay, Corporate Governance and Golden Handshakes
}

\author{
Fabienne Llense*
}

$10 / 10 / 09$

\begin{abstract}
This paper puts forward an explanation of the rapid increase in golden handshake provision in Europe over the last ten years, based on both enhanced investor protection and attractive tax codes for severance pay. This article takes up a framework in which asymmetric information about the quality of the match between CEO and firm explains the use of golden handshakes nfor CEOs. It shows how corporate governance and taxation can modify the magnitude and the use of golden handshakes and thus CEO turnover rates. The second-best optimal taxation rate depends on the kind of private benefits accorded to the CEO. I show that golden handshakes should be taxed in the same way as CEO incomes. However, nonpecuniary private benefits strengthen the agency cost and require some transfers for firms providing parachute-type contracts. In effect, this means partial exemption. An improvement in the quality of corporate governance should lead to smaller golden handshakes, higher turnover-performance sensitivity and the disappearance of advantageous tax codes for termination pay.
\end{abstract}

Classification JEL : G34, H32, J33, J44.

Keywords: CEOs turnover, Corporate governance, Golden handshakes, Optimal taxation, Severance pay.

\section{Introduction}

In European countries, the CEO turnover rates have greatly increased over the last ten years, from $3 \%$ in 1995 up to $17 \%$ in $2007 .{ }^{1}$ At the very same time, a convergence has taken place between the properties of the European and American CEO labor markets in terms of CEO departures. The European CEO turnover rate has increased beyond that in America one and the structure of reasons for departure is now very close. Half of the departures are dismissals due to external control (takeovers) or internal control (boardroom disagreements, changes in ownership, etc.). The other half are planned successions (normal

\footnotetext{
*University of Paris 1 Sorbonne CES and Economics Department Ecole Polytechnique. Adresse: Maison des Sciences Économiques, 106-112 Boulevard de l'Hôpital, 75647 Paris Cedex 13. E-mail: Fabienne.Llense@univ-paris1.fr.

${ }^{1}$ Source: Booz \& Co, Strategy+Business (2008)
} 
end of contract or retirement). The well-known accompaniment of these departures is the CEO severance pay, also called 'golden handshakes' or 'parachutes' because of their huge amounts and the soft-landing they allow the CEO in the case of involuntary departure. Golden parachutes are defined as contractual agreements that provide payments to the CEO upon a change in control of the firm. In the United States, more than $72 \%$ of the largest firms use termination agreements for their $\mathrm{CEO}^{2}$, compared with $79 \%$ in France. ${ }^{3}$ These rates of use are quite similar. Most of those payments are approximately equal to three times the CEO's base pay in the United States and between two and three times in France. The magnitude of golden handshakes in Europe is difficult to obtain, but through the reading of economic newspapers seems close to the French practice. ${ }^{4}$

Two hypotheses about work have emerged, based on the observation of the similarities in European countries. The first hypothesis is about the great changes in corporate governance that have affected most European countries in the last ten years, through both legal and functional convergence ${ }^{5}$ in favor of more investor-friendly corporate governance, as shown by Blazy et al. (2009) for France, and by the increase in the Corporate Governance Quotient of the largest European firms over the period 2003-2007 (Krafft et al. (2009)). Corporate governance has been reconsidered and is designed by large European firms and also by European states through legislation, in order to mimic the Anglo-American model and to attract international funds (frequently Anglo-American institutional investors). It has led to large shifts in the shareholdings of the largest publicly-traded firms and to improvements in the firms' outside opportunities. The ways of reorganizing have become broader, alternative solutions exist which improve a firm's performance besides the performance reachable with the incumbent CEO. The increasing use of golden handshakes for CEOs might express how firms and CEOs make their precommitment according to the outside opportunities offered by both the increasing external finance and the shaping of a market for CEOs who have more general skills than before (Frydman and Saks (2005)).

The second hypothesis about work is about the taxation of termination pay which is very attractive in most European countries. European tax codes for firms are characterized by perfect deductibility of severance pay as 'normal expenses' just like other CEO compensation. And CEO golden handshakes benefit from an advantageous tax system for severance pay, compared with the taxation of other employment income. More precisely, there are three families of taxation on termination payments in Europe. First, there are the countries with very attractive tax codes characterized by reduced tax rates for termination payments: Italy, Austria (6\%), Greece (which applies a 20\% rather than $40 \%$ rate), and Switzerland (taxes on severance pay are one fifth of the ordinary tax rate). Secondly, there are the countries that implement an exemption up to a maximum legal amount, such as France (around 200,000 euros), Denmark (around 60,000 euros), Norway, Spain, the United Kingdom and Luxemburg. And finally, there are the countries where taxes on severance pay are exactly the same as the tax on employment income, as in Germany since 2006 or Sweden. However, some countries have very recently begun to make changes in taxes on golden handshakes. France has reduced the amount up to which there is some tax exemption on severance pay. Germany has adopted the same taxation as for other compensation and the Netherlands has chosen a $30 \%$ tax on companies for "disproportionate exit bonus payments" to those earning more than 500,000 euros. These countries have been led by the desire to counter excesses in terms of CEO

\footnotetext{
${ }^{2}$ Small, Smith and Yildrin (2007) on S\&P500

${ }^{3}$ Sourve: Hewitt

${ }^{4}$ Source: Proxinvest France

${ }^{5}$ Vocabulary introduced by Coffee (1999)
} 
golden handshakes.

From these observations and without taking into account equity or public dissatisfaction, it is worth studying the impact of corporate governance changes and of severance pay taxation on CEO termination agreements to understand how these affect the magnitude and the frequency of golden handshakes and also the impact on CEO turnover rates. Finally, it raises the question of the optimal taxation of those golden handshakes

To the best of my knowledge, these two questions have not yet been addressed.

The benchmark model is introduced in the second section. In the third section, the effects of the legal and tax environment on the magnitude and the use of golden handshakes are analyzed. Then, in the fourth section, the second-best optimal tax rates are determined according to the nature of the CEO's private benefits which are linked to corporate governance. In the fifth section the results are summarized. And the final section concludes.

\section{The basic model}

Theories of corporate finance, such as those put forward by Choe (1998) and Tirole (2006), help us to understand the existence of these deferred compensations as the efficient result of contractualization between the shareholders and the CEO. The intuition is the following: the CEO must share information about the quality of his matching with the firm in order to allow the board to take the right decision in terms of continuation or liquidation ${ }^{6}$ and the firm's restructuring if performance is poor (the matching quality between the CEO and the firm is bad). Due to asymmetric information, golden parachutes are used to force the CEO to tell the truth about the firm's health under his management. This paper takes up Tirole's modeling of this information sharing issue. ${ }^{7}$

\subsection{The issues of matching quality and moral hazard}

The timing of the model is the following. First, the CEO is hired by a firm and the two parties sign a termination agreement. This signature takes place under symmetric information for both parties. The CEO has no ex ante private information before his association with the firm, he only learns about the match-quality once he is under contract. Even if he was the best candidate for the firm ex ante, there is uncertainty about the effective quality of the firm-CEO matching which leads to some information gathering problems. Indeed, the signal about the quality of the matching is the CEO's private information. He decides whether to manipulate this information or not and, accordingly, he chooses the signal he wants to send to the board of directors. At this stage of the decision to continue the association or to stop it (by selling the firm's assets and by replacing the incumbent CEO) the board of directors cannot observe the signal by itself and need the report of the CEO. It can be thought of as soft information which becomes hard information, but always too late to allow the board to take a strategical decision, based on observation or monitoring in time. ${ }^{8}$ Nevertheless, the signal is assumed to be contractible. The

\footnotetext{
${ }^{6}$ The liquidation value is the estimated amount of money that an asset or a company could quickly be sold for, such as if it were to go out of business. By liquidation, I also mean restructuring, by hiring a new CEO and selling assets or through other ways to reorganize the firm.

7 "The theory of Corporate Finance", Princeton University Press 2006

${ }^{8}$ In this article no additional monitoring technology is used, based on the belief that evaluating a CEO's performance in real time is not realistic, as it depends on the degree of expertness of the board of directors and the cost/benefit analysis
} 
contractualisation takes into account the matching quality (good or bad). Based on this assumption, the optimal contract is designed so that the CEO will reveal the quality of the matching. If there is continuation, a moral hazard problem will arise because of the possibility for the CEO to shirk and spend part of his time or energy on other activities with positive spinoffs for himself, called private benefits, and with negative consequences on the firm in general (not enough attention dedicated to the success of the main project). If there is liquidation, the CEO is dismissed and the termination agreement signed at the beginning is applied.

A good matching occurs with a probability denoted by $\alpha$ which is exogeneous and is common knowledge for firms and CEOs. Two matching qualities exist whatever the quality of the global matching between firms and CEOs. This assumption leads to the following restriction on the occurence of a good match: $\alpha \in(0,1) .{ }^{9}$ The probability of success for their common project depends on the quality of the matching, being equal to $r$ when the quality is good, and $q$ when the quality is bad, with $r>q$. The board of directors has two tools to deal with this issue of information gathering: golden handshakes denoted by $T$ and contingent intensity in job security (probability of continuation for the incumbent CEO), which will be further respectively denoted $Z^{r}$ and $Z^{q}$ according to the quality of the matching.

The final probability of success of the project depends not only on the quality of the match (previously mentioned) but also on the CEO's efforts on the job when there is continuation. The quality of the match is assumed to be orthogonal to the later moral hazard which only occurs once there is continuation. In other words, the probabilities $r$ and $q$ are not sufficient statistics for inferring the later effort level chosen by the CEO: either high or low, respectively denoted by $H$ and $L .^{10}$

Let us denote by $r_{H}\left(\operatorname{resp} q_{H}\right)$ the probability of success in the case of a good (bad) match and good behaviour by the CEO and by $r_{L}\left(\operatorname{resp} q_{L}\right)$ when the CEO misbehaves. When he misbehaves, the CEO earns some private benefits denoted by $B$ whatever the quality of the match. The CEO's compensations in the case of continuation and success are denoted by $R_{E}^{S}$ with $S \in\{r, q\}$ the signal reported by the CEO. In the case of total failure the project yields zero and the CEO receives nothing from the firm. The CEOs' compensations in the case of success must be set to elicit his best efforts, whatever the quality of the match. The prior beliefs of the board that the project will succeed under the CEO's good behavior are such that: $p_{H}=\alpha r_{H}+(1-\alpha) q_{H}$. So, the following incentive compatibility constraint must be satisfied to overcome this moral hazard issue:

$$
p_{H} R_{E}^{S} \geqslant p_{L} R_{E}^{S}+B \quad \text { or } \quad R_{E}^{S} \geqslant \frac{B}{\Delta p}
$$

The CEO's compensation in the case of continuation $\left(R_{E}^{S}\right)$ corresponds to the entrepreneur's stake in the firm's income. Without loss of generality, to overcome this moral hazard issue, this constraint is supposed to be binding in the optimization problem and so will not be included in the maximisation program, and this whatever $S \in\{r, q\} .{ }^{11}$ It could be regarded as a kind of limited liability constraint. ${ }^{12}$ The firm

for shareholders. In this model, early warnings are assumed to be the result of the CEO's day-to-day management only.

${ }^{9}$ There cannot exist only one type of match quality at the same time.

${ }^{10}$ As Benos and Weisbach (2004) have stressed, the United States is the country with the lowest level of private benefits but, at the same time, is known for major scandals due to restatements of financial information by public firms.

${ }^{11}$ Introducing a higher $R_{E}^{r}$ than $R_{E}^{q}$ adds nothing to the model. It only leads to a more biting non-manipulation constraint.

${ }^{12}$ A simple utility of reservation can be used instead of this moral hazard constraint. A utility of reservation composed of a monetary part and a non-monetary part, linked to the taste for the prestige of the status of CEO that is inherently non-taxable. 
income is denoted by $R$ in the case of success and is equal to zero in the case of failure of the project. The entrepreneur incentive compatibility constraint implies that the maximum investors' stake is equal to: $R_{I}=p_{H}\left(R-\frac{B}{\Delta p}\right)$ Investors hold $R_{I}$, that is, the expected pledgeable income when the CEO keeps his job whatever the quality of the matching and is paid the minimum amount that induces him to behave in the interest of shareholders. The funding of the project depends on the participation constraints of both investors and CEOs and depends on the revelation of information as introduced in the next section.

\subsection{The funding conditions}

To implement a project which asks for an initial amount of investment denoted by $I$, the entrepreneur needs to be hired by the firm because his personal wealth $A$ is not sufficient to run a firm of this size. The CEO must find external additional funds. A zero-profit condition for investors is assumed. To break even, investors need to earn back at least their initial outlay $I-A$. In the case of termination or changein-control, the firm has a liquidation value denoted by $L$ that can be shared with the CEO through the provision of a severance payment (golden handshakes) denoted by $T$. The liquidation value is the expected market value of the firm after some termination or reorganization. This value depends on the quality of the matching between the newly-hired $\mathrm{CEO}$ and the firm, and also on the way restructurings carried out (sales of assets, layoffs, etc.). The liquidation value lies between the two following extreme cases: $q_{H}\left(R-\frac{B}{\Delta p}\right)<L<r_{H}\left(R-\frac{B}{\Delta p}\right)$.

These inequalities state that investors prefer liquidation when the quality of the match with the incumbent CEO is low. Moreover, the two following assumptions must hold. First, neither the guarantee of continuation for a random CEO, $R_{I}$, nor the termination $\mathrm{L}$ whatever the matching-type quality, could generate enough pledgeable income for investors: $\max \left\{R_{I}, L\right\} \leqslant I-A$. This latter expression indicates that the investors cannot break even by giving a tenure to the $\mathrm{CEO}$ or firing him whatever the quality of the matching .

Secondly, the pledgeable income is sufficient to attract funds as soon as there is automatic liquidation in the case of poor match quality and continuation in the case of good match quality : $\alpha r_{H}\left(R-\frac{B}{\Delta p}\right)+(1-$ $\alpha) L>I-A$.

Hence, shareholders are assumed to agree to financing a project if and only if there is no guaranted tenure for the CEO, in the case of both good or bad signals. As guaranteed tenure prevents funding, by assumption, CEOs must concede some contingent termination to satisfy the investors' break-even constraint. Let $Z^{S}$ denote the probability of continuation when the CEO reports the signal $S$ with $S \in\{r, q\}$ and denote by $\left(1-Z^{q}\right)$ the rate of CEO dismissals caused by forced successions due to a low-quality matching (boardroom disagreements with the CEO's strategy or merger/takeover-related sucessions). The termination rate related to high-quality matching $\left(1-Z^{r}\right)$ is composed of planned successions only (retirement, illness, death, long-expected changes). The investors' participation constraint is written:

$$
\begin{gathered}
\alpha\left(Z^{r} r_{H}\left(R-\frac{B}{\Delta p}\right)+\left(1-Z^{r}\right) L\right)+(1-\alpha)\left(Z^{q} q^{H}\left(R-\frac{B}{\Delta p}\right)+\left(1-Z^{q}\right)(L-T)\right) \geqslant I-A \\
\text { with } \quad Z^{r}<1 \quad \text { and } \quad Z^{q}<1
\end{gathered}
$$

These assumptions imply that a contract with no liquidation in the case of poor performances is dominated by a contract with some liquidation. If there is no scope for manipulation, the optimal employment rule for the board is to liquidate the firm or to restructure and dismiss the CEO as soon 
as the project value for the investors is negative, i.e $Z^{q}=0$ and $Z^{r}=1$. But the threat of dismissal could induce the CEO to hide information about the project's success by sending a false signal about the quality of the matching to the board of directors. Due to this threat of manipulation, they must consider a no-manipulation constraint in order to guarantee that the CEO tells the truth. This is a second best environment due to this additional incentive compatibility constraint. There are two scenarii: one with an informed CEO (the CEO has information about the quality of the matching before he takes the decision to manipulate), the other with an uninformed CEO (the CEO does not know the true quality before sending the message to the board). In the following, the CEO is assumed to be informed about the match quality when he takes the decision to manipulate or not. The CEO chooses to falsify the signal only if the quality of the matching is bad. The optimal contract will satisfy this assumption. There is a marginal falsification cost denoted by $\tau$, which is constant and decreases the probability of success by $0<\tau<q_{H}{ }^{13}$. To relax the truth-telling constraint, the provision of a severance payment, denoted by $T$, is authorized. So that the no-manipulation constraint is written:

$$
Z^{q} q_{H} R_{E}^{q}+\left(1-Z^{q}\right) T \geq Z^{r}\left(q_{H}-\tau\right) R_{E}^{r}
$$

The expected payoff when the CEO reveals the true quality of the matching in the case of a low-quality matching must be at least equal to the expected payoff of the $\mathrm{CEO}$ when he conceals information by reporting the r-signal, despite the manipulation cost, to benefit from the higher continuation probability $Z^{r}$. There is no need for a parachute in the case of dismissal when the matching quality is good. Such a parachute hardens the incentive compatibility constraint without increasing the CEO's incentive to tell the truth or to behave well. It is optimally set equal to zero.

The CEO is assumed risk-neutral, his expected utility denoted $U_{E}($.$) corresponds to the entrepreneur$ expected payoff with a labor contract characterized by $\left(Z^{q}, T\right)$ :

$$
U_{E}\left(Z^{q}, T\right)=\alpha\left[Z^{r} r_{H} R_{E}^{r}\right]+(1-\alpha)\left[Z^{q} q_{H} R_{E}^{q}+\left(1-Z^{q}\right) T\right]-A
$$

It could also be written as the net present value of the project ${ }^{14}$ :

$$
U_{E}\left(Z^{q}, T\right)=\alpha\left[Z^{r} r_{H} R+\left(1-Z^{r}\right) L\right]+(1-\alpha)\left[Z^{q} q_{H} R+\left(1-Z^{q}\right) L\right]-I
$$

The CEO has always ex ante preferences between continuation and termination in the case of poor matching quality and the following assumption must hold: $q_{H} R-L \neq 0$. If $q_{H} R-L>0$ the CEO wants to stay at the head of the firm even in the case of poor matching. The net present value in the case of poor matching is higher than the liquidation value and determines his preference for a continuation-contract in this case. This CEO will be called a continuation-type CEO in this paper. In the opposing case, the CEO prefers termination and the provision of a parachute payment.

\subsection{The optimal labor contract}

Thanks to the ability to distinguish between a planned succession (normal rate of termination in the case of good matching) and a forced succession (occurring in the case of poor performance), the parachute

\footnotetext{
${ }^{13}$ The marginal falsification cost could depends on the quality of the corporate governance (quality of the firm's accounting system, monitoring, blockholders, etc.), or on the institutional properties of the economy (shareholders protection, stakeholder representation)

${ }^{14}$ According to the zero profit condition, the CEO receives the entire social surplus created through the project.
} 
is only paid in the latter case, given that the quality of the match is assumed to be contractible. The non-continuation rate in the case of good matching $1-Z^{r}$ is regarded as planned successions.

To obtain the optimal contract, the social planner maximizes the CEO's expected utility (4) subject to: the economy's resource constraint (5), the no-manipulation constraint (6) and the nonnegativity constraints (7) (the probability of continuation in the case of poor matching and the severance pay cannot take negative values). The resource constraint of the economy states that the expected production minus the expected CEO compensation paid by the firm and the fraction of output raised by the state denoted by $g$ is equal to the investors' initial outlay as capital markets are competitive. The optimal contract is characterized by the couple $\left(Z^{q *}, T^{*}\right)$, solution of the following program:

$$
\max _{Z^{q}, T} U_{E}\left(Z^{q}, T\right)=\alpha\left[Z^{r} r_{H} R_{E}^{r}\right]+(1-\alpha)\left[Z^{q} q_{H} R_{E}^{q}+\left(1-Z^{q}\right) T\right]-A
$$

subject to:

$$
\begin{gathered}
\alpha\left[Z^{r} r_{H}\left(R-R_{E}^{r}\right)+\left(1-Z^{r}\right) L\right]+(1-\alpha)\left[Z^{q} q_{H}\left(R-R_{E}^{q}\right)+\left(1-Z^{q}\right)(L-T)\right]-g \geq I-A \\
Z^{q} q_{H} R_{E}^{q}+\left(1-Z^{q}\right) T \geq Z^{r}\left(q_{H}-\tau\right) R_{E}^{r}
\end{gathered}
$$

and subject to the following nonnegativity constraints:

$$
Z^{q} \geq 0 \quad \text { and } \quad T \geq 0
$$

The optimal contract is obtained with $g=0$ through an optimization under linear inequality constraints (See proof in Appendix 1).

This contract is characterized by two corner solutions according to the CEO's ex ante preferences. When $q_{H} R-L>0$, the cheapest way to prevent manipulation is to concede some continuation in the case of poor matching such that $Z_{q}^{*}=\frac{Z^{r}\left(q_{H}-\tau\right) R_{E}^{r}}{q_{H} R_{E}^{q}}=\frac{Z^{r}\left(q_{H}-\tau\right)}{q_{H}}$ and to grant no severance payments to the CEO $T^{*}=0$. As the moral hazard constraint is assumed to be binding ${ }^{15}$ in both types of matching quality, as previously mentioned $R_{E}^{r}=R_{E}^{q}=R_{E}$ such that $Z_{q}^{*}=\frac{Z^{r}\left(q_{H}-\tau\right)}{q_{H}}$. This optimal contract is called a continuation-type contract. At the optimum, both the investors' participation and the no-manipulation constraints are binding, with $Z_{c}^{r}=\frac{(I-A)-L}{P_{H}^{-}\left(R-R_{E}\right)-L\left(1-\frac{\tau(1-\alpha)}{q_{H}}\right)}$ and $P_{H}^{-}=\alpha r_{H}+(1-\alpha)\left(q_{H}-\tau\right)$.

When $q_{H} R-L<0$, the cheapest way to prevent manipulation is to provide some severance payments $T^{*}=Z^{r}\left(q_{H}-\tau\right) R_{E}^{r}=Z^{r}\left(q_{H}-\tau\right) R_{E}$ and a null probability of continuation in the case of poor quality of the matching, $Z_{q}^{*}=0$. Both the investors' participation and the no-manipulation constraints are binding, with $Z_{p}^{r}=\frac{(I-A)-L}{\alpha\left(r_{H} R-L\right)-P_{H}^{-} R_{E}}$. This optimal contract is called a parachute-type contract and is more signal-sensitive than the continuation-contract.

The optimal contract in this second-best environment resulting from the existence of a truth-telling constraint shows that the provision of a golden handshake is the best contract under the condition that the CEO's ex ante preference in the case of poor performance is to quit the firm rather than to continue. Otherwise, the best contract would be for the firm to make some concessions in terms of the CEO's continuation in the job by precommiting a positive probability of continuation in the case of poor performance. It makes the contract less contingent. ${ }^{16}$ Hence, as already shown by Choe and Tirole, the

\footnotetext{
${ }^{15}$ Increasing the revenue of the CEO when the matching quality is good doesn't set any incentive goal and is a pointless expense for the firm

${ }^{16}$ sufficiently close to the planned one, i.e the initial duration of the contract when the matching quality is good enough
} 
provision of golden handshakes contributes to efficiency by allowing investors to get enough pledgeable income by using the cheapest way to compensate the CEO for truth-telling. In the economy, the turnover rate depends on the ratio of good-quality matching, on CEO preferences in the case of poor performance, on the taxation of severance pay and on the liquidation value of the firm.

\section{The effect of the legal and tax environments on CEOs' termi- nation contracts}

\subsection{The legal environment}

The magnitude of golden handshakes depends on three main variables which are intimately related to corporate governance quality. First, there is a positive association between the golden handshakes magnitude and the present value of the CEO's compensation. The present value of the CEO's compensation is directly linked to the level of the private benefits $B$. Corporate governance improvement can decrease the magnitude of the private benefits that the CEO can grant to himself by increasing the general quality of the monitoring in the firm. This decreases the size of the moral hazard problem and decreases private benefits which are unlawful thanks to recent improvements in investor protection, like, for instance, most non-pecunary private benefits. Indeed, to give evidence that non-pecuniary private benefits have positive spinoffs for the CEO and negative consequences on the firm seems more easy than to do the same for pecunary benefits, such as multiple directors' seats in other companies that can be justified as network maintenance essential for the project's success. Diminished private benefits means smaller golden handshakes.

The cost of manipulation is the second variable which increases with the quality of corporate governance. The passing of accounting standard rules which are more restrictive increases the cost of manipulation for the managers and so decreases the magnitude of the golden handshakes. Moreover, an increase in the cost of manipulation decreases the duration of contracts when the performance is good and also the concessions made when performance is bad. Indeed, the continuation-type contract is all the more

signal-sensitive when the falsification cost is high: $\frac{\partial Z^{q *}}{\partial \tau}=\frac{q_{H}-\tau}{q_{H}} \frac{\partial Z^{r}}{\partial \tau}-\frac{Z^{r}}{q_{H}}<0$. In the termination-type contract, the magnitude of the golden handshake decreases when the cost of manipualtion increases: $\frac{\partial T^{*}}{\partial \tau}=R_{E}^{q}\left(q_{H}-\tau\right) \frac{\partial Z^{r}}{\partial \tau}-Z^{r}<0$. The third variable, the initial duration of the contract, will decrease when there is improvement in corporate governance and in this way the magnitude of the golden handshakes goes down. Better investor protection and more generally any increase in corporate governance should decrease the magnitude of golden handshakes. The present value of the CEO's compensation can correspond to the CEO's annual compensation, the CEO's compensation between two meetings of the board of directors ${ }^{17}$, or to the remainder of the CEO's compensation before the natural termination of the contract. The observed magnitude of CEO golden handshakes, two to three years of total compensation in France, for instance, seems closer to the third hypothesis. The Golden handshake level is higher than predicted by these types of model ${ }^{18}$. For instance, if a CEO has a compensation of 2 millions euro by a year, an initial duration of his mandate of five years (and if he signals that the matching is bad at the end of the second year of his contract), with $Z^{r}=0.89$, based on the $3 \%$ annual probability of

\footnotetext{
17 in which case the parachute size depends on the frequency of the meetings

${ }^{18}$ Without a non-competitive clause
} 
being fired when performance is good in Europe (Booz and Co), $\tau=0.05$ and the firm's capitalization has fallen by $35 \%$, then the parachute is equal to 1.068 million euros.

The use of termination agreements including golden handshakes depends on corporate governance quality and more generally on the legal framework through its effect on the liquidation value of the firm. Indeed, institutional variables such as corporate governance rules linked to legal rules have some effects on the ways in which firms carry out their restructuring. Atanassov \& Kim (2008) have shown that in a country with strong employment protection legislation (EPL), characterized by strong unions and rigidity in employment contracts, the likelihood of reorganizing the firm by dismissing the CEO is lower than in an economy with a lower EPL. Whereas, with strong investor protection legislation (IPL), characterized by weak takeover defences, for example, the likelihood of dismissing the CEO is higher than when the IPL is weak. In the framework of this paper, these results are explained. In a high IPL and low EPL economy, the termination-type CEOs should be more numerous. As shown by Pagano and Volpin (2005) a low EPL will, for most of the time, be combined with a high IPL and vice versa. In a country characterized by high EPL and low IPL, the liquidation values of the companies are lower (ceteris paribus), based on the fact that high employment contract rigidity increases the cost of restructuring the firm or decreases the likelihood of takeover bids. ${ }^{19}$ Pagano and Volpin (2005) interpret these empirical facts by arguing that in countries with high EPL, CEOs and their employees collude in order to avoid takeovers and in this way make their employment more durable. If the country has weak EPL and strong IPL, the liquidation value of the firms will be higher, in general, for a firm with similar characteristics (sectors, capital intensity, etc.) than in a country with strong EPL and weak IPL, leading to a higher CEO turnover rate. So the legal environment has some implications for CEO preferences and on the frequency of CEO contracts which include golden handshakes. In European countries, big changes in investor protection might have increased the number of termination-type CEOs and the number of termination contracts with golden handshakes.

The predictions in terms of $\mathrm{CEO}$ turnover rates are simple. In a country characterized by continuationtype CEOs, the rate of turnover must be lower: TURNOVER $_{c}=\alpha\left(1-Z^{r}\right)+(1-\alpha)\left(1-Z^{q}\right)$, with $Z^{q} \in(0,1)$ and the likelihood of being fired does not vary too much with the firm's performance. Whereas, in a country characterized by termination-type CEOs, the turnover rate will be higher: TURNOVER $_{p}=$ $\alpha\left(1-Z^{r}\right)+(1-\alpha)$ and there are differences in the likelihood of being fired according to the firm's outcomes. These predictions fit both the Japanese and the US stylised facts. Japan's turnover rate is one of the lowest, at around $10 \%$, and the difference in the likelihood of being fired according to the firm's outcomes rises from $0.7 \%$ in the case of good performance up to $2,4 \%$ when performance is poor. ${ }^{20}$ Whereas the turnover rate of American CEOs is about $16 \%$ and the likelihood of being fired for bad performance is around $7,6 \%$ compared with the $2.2 \%$ rate in the case of good performance. The more termination-type CEOs, the higher the turnover rate of the CEOs in the economy.

Proposition 1 Improvements in corporate governance quality and more investor-friendly legal rules must

\footnotetext{
${ }^{19}$ Shleifer and Summers argue that the takeover value is linked to a break in workers' implicit contracts, but if the layoff costs are high it decreases the expected economic benefits of the takeover.

${ }^{20}$ Being in the bottom $10 \%$ of absolute stock performances. Source: Booz \& Co
} 
decrease the magnitude of CEO severance pay but increase the frequency of their use and in this way increase the CEO turnover rate.

This might explain why sometimes the provision of a golden handshake agreement has been welcomed by the shareholders on the Stock Exchange. Rather than the golden handshake in the strict sense, they welcome the increase in corporate governance which has led to this decision.

The following subsection investigates the effect of taxation and highlights the impact of tax codes on golden handshake provision according to corporate governance quality, which itself depends on investor protection, as Laporta et al. (2000) have already shown.

\subsection{The impact of tax on golden handshakes}

The first stage is to know how the choice of the contract is affected by the tax code. Taxation on employment income and on termination payments allows the government to finance some public spending. Even if tax receipts linked to golden handshakes can be regarded as negligible in comparison with public spending, in France the French National Audit Office has highlighted the shortfall due to the exemption from contributions of severance pay in general, and so explicitly of CEO golden handshakes.

The government raises public revenues using two proportional taxes: a tax on normal employment income denoted by $t$ and a tax on CEO severance payments denoted by $t_{T}$. Although most of the time the income taxes are weakly increasing, the taxes are not written as a linear function of CEO payments. CEO severance pay $T$, CEO compensation in the job $R_{E}^{S}$ and the amount of private benefits $B$ are assumed to belong to the same tax bracket. This assumption seems true for most of the European CEOs of publicly-traded companies. ${ }^{21}$ The public revenues are spent as $g$. The balanced budget constraint is written:

$$
g=\alpha Z^{r} r_{H} R_{E}^{r} t+(1-\alpha)\left[Z^{q} q_{H} R_{E}^{q} t+\left(1-Z^{q}\right) T t_{T}\right]
$$

To show how the optimal allocation can be implemented when the state wants to raise a fixed amount of public revenue, I work backward in time. First, the solution for the decentralized competitive economy with taxes is obtained in the present section. Then in the next section the government chooses the taxes which allow it to implement the second-best optimal contracts found in the third section.

The decentralized equilibrium with taxes is characterized by a couple $\left(Z^{q *}\left(t, t_{T}\right), T^{*}\left(t, t_{T}\right)\right)$ solution of the following program (denoted $[\mathrm{Pt}]$ ) which maximizes the CEOs' expected utility under the investors' participation and the no-manîpulation constraints:

$$
\max _{Z^{q}, T} U_{E}\left(Z^{q}, T\right)=\alpha\left[Z^{r} r_{H} R_{E}^{r}\right](1-t)+(1-\alpha)\left[Z^{q} q_{H} R_{E}^{q}(1-t)+\left(1-Z^{q}\right) T\left(1-t_{T}\right)\right]-A
$$

subject to:

$$
\begin{gathered}
\alpha\left[Z^{r} r_{H}\left(R-R_{E}^{r}\right)+\left(1-Z^{r}\right) L\right]+(1-\alpha)\left[Z^{q} q_{H}\left(R-R_{E}^{q}\right)+\left(1-Z^{q}\right)(L-T)\right] \geq I-A \\
Z^{q} q_{H} R_{E}^{q}(1-t)+\left(1-Z^{q}\right) T\left(1-t_{T}\right) \geq Z^{r}\left(q_{H}-\tau\right) R_{E}^{r}(1-t)
\end{gathered}
$$

and subject to the following nonnegativity constraints:

$$
Z^{q} \geq 0, \quad T \geq 0, \quad t>0 \text { and } t_{T}>0
$$

\footnotetext{
${ }^{21}$ For instance in France the lower bound of the last tax bracket is equal to 69,505 euros and in Germany is equal to 250,400 euros.
} 
There are two cases to distinguish, according to the kind of private benefits that the CEO can grant to himself. The private benefits could be monetary rewards of other activities or monetary perks taxable as employment income. For example, the CEO can spend more time (effort) on public or private activities outside his company such as assuming board seats or writing books. In this case the revenues linked to those private benefits are subject to the normal employment income taxation. Otherwise, if private benefits come from the CEO's saving effort, time or from projects with lower probabilities of success but with positive spinoffs (prestige, etc.) for the CEO himself, i.e non-pecuniary perquisites, then those private benefits cannot be taxed as employment income. Nevertheless, each director's seat occupied by the CEO does not have negative spinoffs on the firm's results. Private benefits arise from activities more beneficial for the CEO himself than for the shareholders.

\subsubsection{Private benefits as monetary rewards}

If private benefits take the form of monetary rewards for outside activities (Board of Directors in other large companies and all the pecuniary benefits of shirking) they are subject to taxation. The minimum amount investors pay to provide an incentive to the CEO stays the same as in (1) and, to maximize the pledgeable income, the moral hazard constraint stays identical to the one introduced in Section 2 and is binding: $R_{E}^{S}=\frac{B}{\Delta p}=R_{E}$ with $S \in\{r, q\}$. An optimization under linear inequality constraints is performed (See Appendix 2) to solve the program presented hereinbefore. At equilibrium, in this competitive economy with taxation, the Board signs a continuation-type contract with the CEO, characterized by a positive continuation rate and no golden handshake, written:

$$
Z_{1}^{q *}\left(t, t_{T}\right)=\frac{Z_{1 c}^{r}\left(q_{H}-\tau\right)}{q_{H}} \quad \text { and } \quad T_{1}^{*}\left(t, t_{T}\right)=0
$$

If the following condition holds: $-K_{1}\left(t, t_{T}\right) \leqslant q_{H} R-L$ with $K_{1}\left(t, t_{T}\right)=\frac{q_{H} R_{E}\left(t_{T}-t\right)}{\left(1-t_{T}\right)}$.

In the case of poor matching quality, the continuation rate does not depend on the government's taxes, contrary to the provision of continuation-type contracts which are linked to the tax rates comparison according to the condition on $K_{1}\left(t, t_{T}\right)$.

Otherwise, the investors precommit with the CEO through a parachute-type contract, characterized by no continuation in the case of poor performance but with positive severance payments:

$$
Z_{1}^{q *}\left(t, t_{T}\right)=0 \quad \text { and } \quad T_{1}^{*}\left(t, t_{T}\right)=\frac{Z_{1 c}^{r}\left(q_{H}-\tau\right) R_{E}^{r}(1-t)}{\left(1-t_{T}\right)}
$$

if the following condition holds: $q_{H} R-L \leqslant-K_{1}\left(t, t_{T}\right)$.

The magnitude of the golden handshake decreases with the employment income tax and increases with the tax on severance pay. This result is corroborated by the American firms who do their best to gross-up the amount of severance pay demanded by their CEO in order to furnish this amount in the case of the CEO's dismissal. Indeed, gross-up golden handshakes in the United States are designed to offset the impact of the excise tax imposed on golden parachutes, and correspond to a forced provision by the firm to make up for the CEO's losses in term of severance payments and to deal with the truth-telling constraint. The lower the taxation on the employment income, the lower is the need for this type of gross-up strategy by the firm.

The use of a golden handshake agreement increases as soon as the income tax is higher than the tax on severance pay. For a given set of parameters, the parachute-type contract is more likely than the 
continuation-type one. The critical value, which was nil before, becomes the threshold $-K_{1}\left(t, t_{T}\right)$. This is because the contractualization with some golden handshakes is less expensive than with some continuations in the case of poor performance. In other words, for some firms the opportunity cost of conceding some continuation becomes too high in comparison with the gain of using the most attractive tool of compensation in terms of taxation.

If $t_{T}<t$, the optimal contract consists in continuation if $0<-K_{1}\left(t, t_{T}\right) \leqslant q_{H} R-L$. Otherwise, when $q_{H} R-L \leqslant-K_{1}\left(t, t_{T}\right)$ the optimal contract consists in a golden handshake provision. On the contrary, if the severance pay tax is higher than the income tax, the contract with continuation in the case of poor performance is more probable than the parachute one. When $t_{T}>t$, the optimal contract consists of continuation if $-K_{1}\left(t, t_{T}\right) \leqslant q_{H} R-L$ and of severance pay provision if $q_{H} R-L \leqslant-K_{1}\left(t, t_{T}\right)$. It is illustrated by Figure 1. An increase in the tax burden on severance pay will decrease the incidence of golden parachute provision because it increases the critical value $K_{1}\left(t, t_{T}\right)$ and so the frontier between the regimes of contract. Taxation modifies the cheapest way for the firm to compensate the CEO, leading to a shift in the type of offered contract for some sets of parameters $(\mathrm{L}, \mathrm{R})$. As expected, the introduction

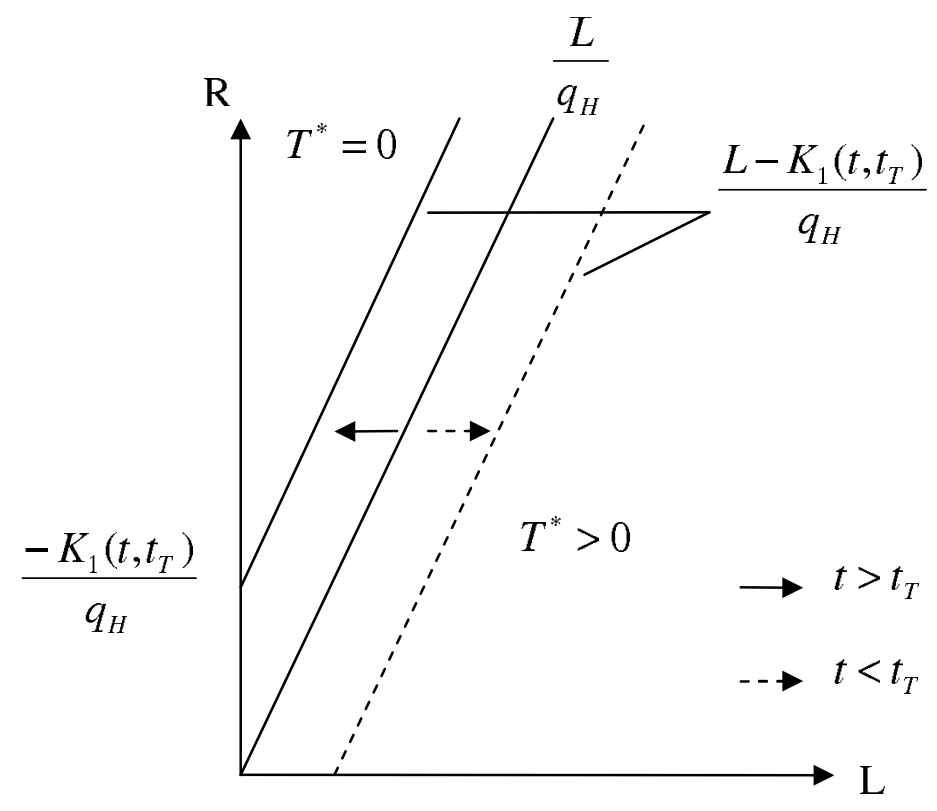

Figure 1: Frontier of types of CEO termination contract

of differences in taxation between the two types of compensation distorts the use of golden handshakes versus continuation (job security) as the optimal precommitment. The fraction of termination-type CEO contracts depends on termination pay taxation. When the employment income taxation is higher than the termination pay taxation, $t_{T}<t$, the fraction of continuation-type CEO contracts decreases.A precommitment with severance pay is more likely than when private benefits were taxable and the turnover should be higher.

Proposition 2 The higher the attractivity of the tax code on severance payments, the higher the CEO turnover rate and the incidence of golden handshakes in the economy. But the magnitude of golden 
handshakes must be lower when the tax code on severance pay is more attractive than the tax code on other employment income.

The CEO rate of turnover will be lower when $t_{T}>t$ as demonstrated by the lower turnover rate in the United States, where the CEOs' golden handshakes bear an additional tax when considered as excessive severance pay. In comparison, European countries' turnover rates are slightly higher on average than in the US and golden handshakes are often exempted from taxation under some thresholds.

\subsubsection{Non-pecuniary private benefits}

When private benefits are regarded as the value of saving time or effort for the CEO or whatever the nonmonetary perks, the minimum amount of the CEO's compensation that elicits the CEO's good behavior increases. Indeed, the moral hazard constraint implies that a higher amount must be paid, given that those private benefits are not subject to the employment taxation, equal to: $R_{E}(t)=\frac{B}{\Delta p(1-t)}$. The agency cost is higher, i.e the moral hazard is strengthened. The optimization program is the same as in Appendix 2 but with $R_{E}^{S}(t)$ instead of $R_{E}^{S}$. The conditions and the optimal values of contracts are different from the previous case in which private benefits were taxable. The contract is a continuation-type and is characterized by:

$$
Z_{2}^{q *}\left(t, t_{T}\right)=\frac{Z^{r}\left(q_{H}-\tau\right)}{q_{H}} \quad \text { and } \quad T_{2}^{*}\left(t, t_{T}\right)=0
$$

if the following condition holds: $-K_{2}\left(t, t_{T}\right) \leqslant q_{H} R-L$ with $K_{2}\left(t, t_{T}\right)=\frac{K_{1}\left(t, t_{T}\right)}{(1-t)}$. Otherwise, the contract is a parachute-type and is characterized by:

$$
Z_{2}^{q *}\left(t, t_{T}\right)=0 \quad \text { and } \quad T_{2}^{*}\left(t, t_{T}\right)=\frac{Z^{r}\left(q_{H}-\tau\right) R_{E}}{\left(1-t_{T}\right)}
$$

if, $q_{H} R-L \leqslant-K_{2}\left(t, t_{T}\right)$. With non-taxable private benefits, the parachute increases with the taxation on severance pay but does not depend any more on income tax. The magnitude of golden handshakes is greater than those with taxable private benefits. Indeed, the agency cost is increased by the strengthened moral hazard constraint and, through the no-manipulation constraint, it implies an increase in the golden handshake magnitude. Moreover, when the moral hazard is strengthened by taxation, i.e the agency cost increases, the taxation has a greater impact on the choice of the type of contract (parachute or continuation) than in the previous subsection (3.2.1). The frontier of the contract is more sensitive to the tax environment.

Proposition 3 An attractive taxation on termination pay implies more parachute-type contracts, all the more when the fraction of non-taxable private benefits is high (and the bigger the parachute).

Once the effects of exogeneous taxation have been understood: what are the tax rates which implement the optimal contracts in this second best environment?

\section{Second-best optimal taxation of golden handshakes}

The aim of this section is to identify the second-best optimal taxation on golden handshakes. By comparing the socially optimum contract (Section 2) to the equilibrium conditions for the competitive economy 
with taxation (Section 3.2), we can identify the second-best tax rates. The socially optimal contract can be achieved in the competitive economy by tax rates verifying the following conditions, $\forall i \in 1,2$ :

$$
\begin{array}{ccc}
Z_{i}^{q *}\left(t^{*}, t_{T}^{*}\right)=Z^{q *} \quad \text { when } & q_{H} R-L>0 & \text { s.t } \\
K_{i}\left(t, t_{T}\right)=0 & & \\
& & \\
T_{i}^{*}\left(t^{*}, t_{T}^{*}\right)=T^{*} \quad \text { when } \quad q_{H} R-L<0 & \text { s.t }
\end{array}
$$

The second best tax rates must satisfy the following necessary condition, which makes the frontier between the type of contracts in the economy with taxation identical to the optimal frontier of contracts:

$$
K_{i}\left(t^{*}, t_{T}^{*}\right)=0 \quad \Rightarrow \quad t_{T}^{*}=t^{*}
$$

The optimal taxation prevents the use of continuation-type contracts instead of parachute-type contracts when $q_{H} R-L>0$ and vice versa when $q_{H} R-L<0$. These second-best tax rates are determined by the government's budget constraint. The government tax choices are restricted by its balanced budget constraint:

$$
g=\alpha Z^{r} r_{H} R_{E} t^{*}+(1-\alpha)\left[Z^{q *}\left(t^{*}, t_{T}^{*}\right) q_{H} R_{E} t^{*}+\left(1-Z^{q}\right) T^{*}\left(t^{*}, t_{T}^{*}\right) t_{T}^{*}\right]
$$

And finally, the investors must break even, i.e the investors'participation constraint must be satisfied.

\subsection{CEOs with homogeneous preferences}

\subsubsection{CEOs are continuation-type}

When CEOs prefer continuation-type contracts at the optimum, there is no restriction on taxes on severance pay given that there are no golden handshakes provided in this case. To implement the optimal contract, whatever the property (taxable or not) of private benefits, the income tax is determined by the government's balanced budget constraint and is finally equal to:

$$
t^{*}=\frac{g}{Z^{r} R_{E}\left(\alpha r_{H}+(1-\alpha)\left(q_{H}-\tau\right)\right)}=\frac{g}{Z^{r} R_{E} P_{H}^{-}}
$$

The investors' participation constraint is automatically satisfied due to the independence of the continuation probability from the taxes rate.

\subsubsection{CEOs are termination-type}

Most of the time golden handshakes are not totally free of taxes or contributions. This article produces a way to understand these partial tax exemptions or reduced tax rates based on type of CEO's private benefits. To implement the optimal contract when the preferences of CEOs are in favour of termination contracts, the State should at first sight apply a zero taxation on CEOs' severance pay to get: $T^{*}\left(t^{*}, t_{T}^{*}\right)=$ $T^{*}$. But this zero taxation distorts the choice of contract in favor of the compensation which is the most attractive in terms of taxation, the severance pay in this case. To obtain the socially optimal contract, for the right preference-type CEOs, the government must fix equal tax rates to recover the optimal frontier of contracts. If private benefits (B) are partially taxable, with a taxable fraction denoted by $f$ and a 
non-taxable fraction $1-f$, such that: $B=f B+(1-f) B$. The new critical value between the frontier of contracts can be written: $K_{3}\left(t, t_{T}\right)=f K_{1}\left(t, t_{T}\right)+(1-f) K_{2}\left(t, t_{T}\right)$ and implies a golden handshake magnitude of:

$$
T^{*}\left(t, t_{T}\right)=f T_{1}^{*}\left(t, t_{T}\right)+(1-f) T_{2}^{*}\left(t, t_{T}\right)=\frac{f Z^{r}\left(q_{H}-\tau\right) R_{E}(1-t)}{\left(1-t_{T}\right)}+\frac{(1-f) Z^{r}\left(q_{H}-\tau\right) R_{E}}{\left(1-t_{T}\right)}
$$

To implement the optimal contract, the State must fix $K_{3}\left(t^{f *}, t_{T}^{f *}\right)=0$. It means equal tax rates on termination pay and employment income. The golden handshake with optimal second-best tax rate is written:

$$
T^{*}\left(t^{f *}, t^{f *}\right)=\frac{1-t^{f *} f}{1-t^{f *}} T^{*}
$$

If $t^{*}=t_{T}^{*}$ the severance pay is higher than it should be in the optimal contract. The investors' breakeven constraint is no longer satisfied. It leads the State to make a transfer to firms who provide golden handshakes such that the investors can break even and finance the project. The transfer from the State to the investors is equal to the differential:

$$
d^{f *}=T^{*}\left(t^{f *}, t^{f *}\right)-T^{*}=\frac{t^{f *}(1-f)}{1-t^{f *}} T^{*}
$$

It leads to the following proposition:

Proposition 4 When private benefits are partially non-taxable:

a- The second-best tax rates allowing the State to implement the optimal contract are equal to:

$$
t^{f *}=t_{T}^{f *}=\frac{g}{Z^{r} R_{E}\left(\alpha r_{H}+(1-\alpha)\left(q_{H}-\tau\right) f\right)}
$$

In this last case, the second-best tax rates are higher than with taxable private benefits and increase in the fraction of non-taxable private benefits.

$b$ - The transfer granted to the firm in the case of the CEO's dismissal is:

$$
d^{f *}=\frac{(1-f)}{1-t^{f * f}} t^{f *} T^{*}\left(t^{f *}, t^{f *}\right)
$$

It comes to a partial exemption or reduced tax rate on golden handshakes. Indeed, this transfer is lower than the amount raised by the State through the taxation on severance pay, $t^{f *} T^{*}\left(t^{f *}, t^{f *}\right)$.

There are two extreme cases when private benefits are entirely non-taxable or entirely taxable. When private benefits are entirely non-taxable it corresponds to $f=0$, The taxation on golden handshakes increases their magnitude beyond the optimal level and threatens the participation of investors. It leads the State to make a lump-sum transfer to the firms that provide golden handshakes, equal to $d^{p *}$ :

$$
d^{p *}=T^{*}\left(t^{p *}, t^{p *}\right)-T^{*}=\frac{t^{p *}}{1-t^{p *}} T^{*}=t^{p *} T^{*}\left(t^{p *}, t^{p *}\right)>0
$$

This transfer boils down to a total exemption for golden handshakes, given that the taxes on golden handshakes that each CEO pays are returned as a lump-sum transfer to the firm. Non-taxable private benefits induce an increase in the CEO's compensation due to the moral hazard constraint which determines the minimum amount the firm must pay its CEO. This raise is passed on to the severance payments through 
the no-manipulation constraint. In addition, the severance payments tax increases the gross golden handshakes. The State needs to balance its budget constraint: $g=\alpha Z^{r} r_{H} R_{E} t^{p *}+(1-\alpha)\left[T^{*}\left(t^{p *}, t_{T}^{p *}\right) t^{p *}-d^{p *}\right]$. The investors' participation constraint is written: $\alpha\left[Z^{r} r_{H}\left(R-R_{E}\right)+\left(1-Z^{r}\right) L\right]+(1-\alpha)\left(L-T^{*}\left(t^{p *}, t^{p *}\right)+\right.$ $\left.d^{p *}\right) \geq I-A$. The second-best tax rates allowing the State to implement the optimal contract are equal and such that:

$$
t^{p *}=t_{T}^{p *}=\frac{g}{Z^{r} R_{E} \alpha r_{H}}
$$

These second-best tax rates are higher than those for taxable private benefits.

The second limit case arises when private benefits are entirely taxable. The tax rate is exactly the same as for continuation-type CEOs:

Proposition 5 If private benefits are taxable, whatever the ex ante CEO preferences, the second-best tax rates allowing the State to implement the optimal contract are equal and such that:

$$
t^{*}=t_{T}^{*}=\frac{g}{Z^{r} R_{E} p_{H}^{-}}
$$

and there is no need for transfers from the State.

The effective tax rates on employment income and on golden handshakes are highest when the fraction of non-taxable private benefits is high due to the State's transfers granted to companies that provide golden handshakes to their CEOs which creates a shortfall in public revenues. To summarize the results on taxation levels:

$$
t_{T}^{*}<t_{T}^{f *}<t_{T}^{p *} \quad \text { as } \quad \frac{\partial t_{T}^{f *}}{\partial f}<0
$$

Moreover, the exemption for golden handshakes increases with the fraction of non taxable private benefits:

$$
0<d^{f *}<d^{p *}
$$

This model helps to explain reduced tax rates or tax exemptions for golden handshakes, relative to the kind of private benefits the CEO generates for himself when he shirks. If the kind of private benefits depends on the quality of the corporate governance, then this article expresses a direct link between corporate governance and optimal taxation for CEOs' golden handshakes. Improvements in corporate governance are often regarded as the result of shifts in investor protection legislation, as La Porta et al. (1999) have emphasized. Higher investor protection (transparency rules, accounting standards, the complete registration of related party transaction, etc.) leads to an environment of better corporate governance where the quantity and the quality of the information automatically gathered by the Board and the CEO is growing. The ways in which the CEO can dispossess shareholders are diminished. Monetary perks are easier to constrain and most of the time known by the employer because they are taxable. One of the first improvements due to better corporate control must be the increasing transparency, both in terms of strategy and of accountability. According to this view the fraction of private benefits which is non-taxable must also decrease with the improvement of corporate governance. Hence, advantageous tax codes in Europe can be explained as the result of some optimal taxation if private benefits were essentially non-taxable in periods of low corporate governance. Nowadays, with the increasing transparency on the European stock exchange, the taxation on golden handshakes should be equal to or closer to the employement income taxation, depending on the corporate governance quality. 


\subsection{Heterogeneity in CEOs' preferences}

In reality the two types of $\mathrm{CEO}$ coexist. Given that the government must fix the same optimum tax rates for CEOs' compensation and severance pay, the second best tax rate could be determined for CEOs with heterogenous preferences. The CEO-firm matchings are heterogeneous in two dimensions, the liquidation value of the firm and the outcome of the project in the case of success $R$. This heterogeneity can be illustrated by different values of assets or capital intensity, with the same investment $I$, the outcome $R$ in the case of success and the liquidation value of the firm, which could be different depending on the firm and sector characteristics. Let $\gamma$ denote the fraction of CEOs with continuation-type preferences. This fraction depends on the distribution of both liquidation and outcome values in this economy, which could themselves depend on some institutional variables such as the rigidity of the employment protection legislation (EPL) or the investor protection legislation (IPL). The fraction of continuation-type contracts is determined by the frontier of contracts, which, in turn, depends on taxation.

To determine the optimal contracts with heterogeneity, the State maximizes a utilitarian welfare function through a weighted average of the expected utility of the two types of CEO according to their proportion in the economy. The type of the CEO is distinguished by $c$ for a continuation-type CEO and $p$ for a parachute-type CEO. The program becomes with participation constraints and no-manipulation constraints for each type of CEO:

$$
\max _{Z_{c}^{q}, Z_{p}^{q}, T_{c}, T_{p}} \gamma U_{E}^{c}\left(Z_{c}^{q}, T_{c}\right)+(1-\gamma) U_{E}^{p}\left(Z_{p}^{q}, T_{p}\right)
$$

subject to:

$$
\begin{gathered}
\gamma\left[\alpha\left[Z_{c}^{r} r_{H}\left(R-R_{E}\right)+\left(1-Z_{c}^{r}\right) L\right]+(1-\alpha)\left[Z_{c}^{q} q_{H}\left(R-R_{E}\right)+\left(1-Z_{c}^{q}\right)\left(L-T_{c}\right)\right][-\gamma g \geq \gamma(I-A)\right. \\
(1-\gamma)\left[\alpha\left[Z_{p}^{r} r_{H}\left(R-R_{E}\right)+\left(1-Z_{p}^{r}\right) L\right]+(1-\alpha)\left[Z_{p}^{q} q_{H}\left(R-R_{E}\right)+\left(1-Z_{p}^{q}\right)\left(L-T_{p}\right)\right]\right] \\
-(1-\gamma) g \geq(1-\gamma)(I-A) \\
Z_{c}^{q} q_{H} R_{E}+\left(1-Z_{c}^{q}\right) T_{c} \geq Z_{c}^{r}\left(q_{H}-\tau\right) R_{E} \\
Z_{p}^{q} q_{H} R_{E}+\left(1-Z_{p}^{q}\right) T_{p} \geq Z_{p}^{r}\left(q_{H}-\tau\right) R_{E}
\end{gathered}
$$

and subject to the following nonnegativity constraints:

$$
Z_{c}^{q} \geq 0, \quad Z_{p}^{q} \geq 0, \quad T_{c} \geq 0 \quad \text { and } \quad T_{p} \geq 0
$$

The optimal contracts are the same as usual according to the CEO's type (See Appendix 3) such that for continuation-type CEOs :

$$
Z_{c}^{q m i x *}=\frac{Z_{c}^{r}\left(q_{H}-\tau\right)}{q_{H}} \text { and } T_{c}^{m i x *}=0
$$

whereas for parachute-type CEOs, the contract is:

$$
Z_{p}^{q m i x *}=0 \quad \text { and } \quad T_{p}^{m i x *}=Z_{p}^{r}\left(q_{H}-\tau\right) R_{E}
$$

In reality, the type of the CEO is not directly observable by the State. The contracts of CEOs are secret, so it only knows about the golden handshakes when they are reported to the tax authorities. Hence, the 
State wants to set a uniform taxation and not separate taxation for continuation-type and parachute-type CEOs.

If the private benefits are taxable, the optimal tax rates whatever the fraction of CEOs of each preference group satisfy the government's balanced budget constraint:

$$
g=t \alpha r_{H} R_{E}\left[\gamma Z_{c}^{r}+(1-\gamma) Z_{p}^{r}\right]+(1-\alpha)\left[\gamma Z_{c}^{q m i x *} q_{H} R_{E} t+(1-\gamma) T_{p}^{m i x *} t_{T}\right]
$$

and such that:

$$
K_{1}\left(t^{m i x *}, t_{T}^{m i x *}\right)=0
$$

If private benefits are non-taxable, the number of CEOs of each preference-type has more importance, given that the amount raised through the tax on severance pay is immediately given back to the firms who dismiss their CEO, and pay them a parachute as shown in section 4.1.2. In this latter case, the optimal tax rate, whatever the fraction of CEOs of each preference group, is given by the government's budget constraint:

$$
g=t \alpha r_{H} R_{E}\left[\gamma Z_{c}^{r}+(1-\gamma) Z_{p}^{r}\right]+(1-\alpha)\left[\gamma Z_{c}^{q m i x *} q_{H} R_{E} t\right]
$$

and such that:

$$
K_{2}\left(t^{m i x *}, t_{T}^{m i x *}\right)=0
$$

In the two possibilities, the two tax rates are equal.

Proposition 6 When there is heterogeneity in the CEO types according to the liquidation and the outcome values of the firm they manage.

1) If private benefits are taxable, then the second-best optimal tax rates are:

$$
t^{m i x *}=t_{T}^{m i x *}=\frac{g}{R_{E}\left[\gamma Z_{c}^{r}+(1-\gamma) Z_{p}^{r}\right] p_{H}^{-}}
$$

2) If private benefits are not taxable then the second-best optimal tax rates are:

$$
t^{m i x *}=t_{T}^{m i x *}=\frac{g}{R_{E}\left[\gamma p_{H}^{-} Z_{c}^{r}+(1-\gamma) \alpha r_{H} Z_{p}^{r}\right]}
$$

The continuation-type CEOs subsidize the termination-type CEOs: $t^{*}<t^{m i x *}<t^{p *}$. Indeed, the level of overall taxes is higher when all CEOs are termination-type than when they are all continuation-type.

The tax rates decrease with the fraction of continuation-type CEOs, but stay higher than in the case of taxable private benefits.

The effect of $\gamma$ on the tax rate can be broken down into a composition effect and a size of tax base effect. The composition effect is determined when $Z_{c i}^{r}=Z_{p i}^{r 22}$ and is nil when private benefits are taxable and negative when they are non-taxable. This effect is led by the optimal policy of subsidies for parachutes in the case of non taxable private benefits. The size effect corresponds to the variation of the size of the total tax base with the value of $Z_{c}^{r}$ to compare to $Z_{p}^{r}$. When $\gamma$ increases and $Z_{c}^{r}<Z_{p}^{r}$, the size of the tax

\footnotetext{
${ }^{22}$ Which happens when the $(\mathrm{L}, \mathrm{R})$ is exactly on the frontier of contract. CEOs have no preferences between continuation or termination contracts
} 
base decreases. To obtain a balanced budget constraint, the tax rates must increase. In most cases ${ }^{23}$, as soon as private benefits are non-taxable and $Z_{c}^{r}>Z_{p}^{r}$, the more parachute-type CEOs there are, the higher the taxation rate and the amount of severance pay are. The turnover rate is written:

$$
\begin{gathered}
\left.\operatorname{TURNOVER}_{\text {mix }}=\alpha\left[\gamma\left(1-Z_{c}^{r}\right)+(1-\gamma)\left(1-Z_{p}^{r}\right)\right]+(1-\alpha)\left[\gamma\left(1-Z_{c}^{q}\right)+(1-\gamma)\right], \quad \text { with } Z_{c}^{q} \in\right] 0,1[ \\
\frac{\partial \mathrm{TURNOVER}_{\text {mix }}}{\partial \gamma}=-\left[1+Z_{p}^{r}+\alpha Z_{c}^{r}+Z_{c}^{q}\right]+\alpha Z_{c}^{q}<0
\end{gathered}
$$

As expected, the turnover rate increases with the fraction of parachute-type CEOs in the economy.

\section{Results}

In the first stage, the impact of the legal and tax environment on the magnitude and the use of golden handshakes is investigated to highlight the role of termination pay taxation and changes in corporate governance in the development of golden handshakes. In Europe, the recent and rapid shifts in corporate governance have led to more investor protection through higher transparency and accounting standards. These changes in the legal environment have increased the cost of manipulation $(\tau)$, decreased the CEOs' private benefits $(B)$ and increased the liquidation or restructuring value of the firm $(L)$. Through these variables, the magnitude of the golden handshakes decreases, but the use of a golden handshake agreement is only affected by the liquidation value of the firm (assessed as the alternative to the incumbent CEO). The higher the liquidation values of firms in the economy, the higher the frequency of the use of golden handshakes. It might explain why the provision of golden handshakes is received positively by shareholders and more broadly by the Stock Exchange, as it is regarded as a sign of good corporate governance.

The magnitude of golden handshakes increases in termination pay taxation: an attractive termination pay taxation will increase the size of the golden handshakes granted in the economy. This modelization helps to understand why American firms gross up the amount of the golden handshake demanded by the CEO to furnish this total amount. The impact of taxation on the use of golden handshakes is the one expected. The incidence of golden handshakes provision increases in the tax burden on employment income and decreases as taxes on severance pay increase.

In addition, the quality of corporate governance also has an impact on the kind of CEOs' private benefits and also on the impact of taxation on both the magnitude and the use of golden handshakes. When private benefits are monetary perks which can be taxed, the magnitude of the golden handshakes decreases with employment income tax, whereas non-taxable private benefits induce higher levels of golden handshakes, because the employment income taxation no longer curbs the golden handshakes. The frontier of contracts is more sensitive to tax on termination pay when the private benefits are non-taxable. Hence, shifts in investor protection legislation in Europe combined with attractive tax codes for termination payments might have enhanced the use of golden handshakes in European countries beyond the optimal level.

23

$$
\frac{\partial t^{*}}{\partial \gamma}<0 \quad \text { if } \quad Z_{c}^{r}=Z_{p}^{r} \quad ; \quad \frac{\partial t^{*}}{\partial \gamma}>\text { or }<0 \quad \text { if } \quad Z_{c}^{r}>Z_{p}^{r} \quad ; \quad \frac{\partial t^{*}}{\partial \gamma}>0 \quad \text { if } \quad Z_{c}^{r}<Z_{p}^{r}
$$


In the second stage, the optimal taxation is obtained to better understand differences in tax codes according to corporate governance quality. Optimal taxation of severance pay differs according to the kind of private benefits : taxable or not like other employment income. If the perks or private benefits are monetary rewards of the CEO's other activities, then the tax on severance pay must be equal to the employment income tax. An attractive taxation on severance pay will hedge the use of specific contract-types in favour of golden handshake contracts rather than continuation contracts. If private benefits are non taxable and when the CEO prefers some severance pay rather than some job security, a lump-sum transfer to the firm providing the golden handshake is required. According to the taxable fraction of private benefits, it will boil down to some exemption for golden handshakes. This could be interpreted as the reason for the existence of attractive taxations on severance pay in countries where the main source of private benefits is non-pecuniary. Indeed, as Dyck and Zingales (2004) mentioned, there are three potential sources of private benefits: psychic value, perquisites and dilution. The perquisites are the most visible expropriation technology and an improved corporate governance must prevent this kind of benefit. Hence private benefits should be more taxable when the corporate governance is high. To the best of my knowledge there is no literature on this specific issue and it needs to be developed. If this assumption holds, in periods of low corporate governance quality, the tax code has a duty to be more advantageous for severance pay through reduced tax rates or exemption up to a maximum legal amount as I have shown in this article. If the recent improvement in corporate governance led to fewer opportunities for CEOs to benefit from "non-pecuniary aspects of his entrepreneurial activities such as [...] the kind and the amount of charitable contributions, personal relations with employees, or purchase of production inputs from friends" as expressed by Jensen and Meckling (1976), which are a non-taxable form of perquisities for the CEO, then attractive tax codes for golden handshakes should disappear. This article explains the difference in tax codes depending on the nature of the CEO's private benefits and builds a new bridge between taxation and corporate governance. It puts forward a way to better understand the link between tax codes, golden handshake agreements and corporate governance.

\section{Concluding Comments}

CEOs' severance pay is different from that of other employees. As expected, severance pay for CEOs is less often used when the tax rate on severance pay increases and it is also the case for normal employees' severance pay, as demonstrated by Goerke \& Pannenberg (2009). But interestingly, there are some different results in terms of the magnitude of normal employees' severance pay in Germany. The magnitude of normal severance pay decreases with the taxation on termination pay, contrary to that of CEOs. It comes from the role played by severance pay for employees, analysed as a way to preclude lawsuits in countries where the employment protection legislation is strong (more termination conflicts) and where there is no ground prepared by the law for severance pay agreements. In this latter case, severance pay is negotiated ex post between the two parties. If termination taxation is high, then the employee has less bargaining power as severance pay is quite expensive for the employer.

The difference lies in the role played by severance pay for employees and for CEOs. Severance pay for CEOs overcomes an problem of asymmetric information, whereas severance pay for normal employees is a 
way of reducing dismissal costs ex-post. It follows that the optimal taxation results for golden handshakes discussed in this paper should not be applied to normal employees' severance pay.

At first sight the downward trend in the magnitude of golden handshakes predicted by this model, once corporate governance has been improved, seems to be unrealistic for the United States, as it has never occured. This lack of a downward trend can be explained in this model as the effect of very unattractive tax codes for golden parachutes in the United States. Boards of Directors keep providing large amounts of severance pay and even gross up the value demanded by their CEO.

The efficiency of Anglo-American corporate governance might have been over-estimated all the more in that legislation on this issue, more precisely the Deficit Reduction Act (1984), established a very high norm for golden handshakes (three times the CEO's pay).

To curb the golden parachutes for under-performing company bosses, making the provision of golden parachutes contingent upon performance, as public or employers' associations suggest doing, is not the solution. It might reverse the agency problem by increasing CEOs' incentives to manipulate information or increase the risk of lawsuits ex post due to disagreements about the justification of dismissals. Such a reform would lead to the end of the ad nutum clause and could decrease the mobility of CEOs. It implies extra costs when the contract is broken and may have a harder impact on CEOs' reputations and in this way on the amount of other types of compensation to make up for this risk (for the CEO). Even though the need for severance pay for CEOs can be justified, the size of the golden handshakes and the way in which they are taxed is a topic worth investigating.

\section{Acknowledgements}

I am very grateful to Pierre Cahuc for his advice. I thank all the participants of the Louis-André GérardVaret 2009, Public Economic Theory 2009 and Association Française de Sciences Economiques 2009 conferences for their useful comments.

\section{A Appendix 1}

A modified Lagrangean function is defined by $L(.,$.$) with \lambda_{1}$ the Lagrangean multiplier related to the resource constraints of the economy and $\lambda_{2}$ the Lagrangean multiplier related to the no-manipulation constraint such that:

$$
\begin{array}{r}
L\left(Z^{q}, T\right)=\alpha\left[Z^{r} r_{H} R_{E}^{r}\right]+(1-\alpha)\left[Z^{q} q_{H} R_{E}^{q}+\left(1-Z^{q}\right) T\right]-A \\
+\lambda_{1}\left[\alpha\left[Z^{r} r_{H}\left(R-R_{E}^{r}\right)+\left(1-Z^{r}\right) L\right]+(1-\alpha)\left[Z^{q} q_{H}\left(R-R_{E}^{q}\right)+\left(1-Z^{q}\right)(L-T)\right]\right. \\
-g+A-I]+\lambda_{2}\left[Z^{q} q_{H} R_{E}^{q}+\left(1-Z^{q}\right) T-Z^{r}\left(q_{H}-\tau\right) R_{E}^{r}\right]
\end{array}
$$

The Kuhn and Tucker conditions are the following:

$$
\begin{gathered}
\frac{\partial L\left(Z^{q *}, T^{*}\right)}{\partial Z^{q *}} \leq 0 \\
Z^{q *} \geq 0 \\
Z^{q *} \frac{\partial L\left(Z^{q *}, T^{*}\right)}{\partial Z^{q *}}=0 \Longleftrightarrow Z^{q *}=0 \text { or } \frac{\partial L\left(Z^{q *}, T^{*}\right)}{\partial Z^{q *}}=0
\end{gathered}
$$




$$
\begin{gathered}
\frac{\partial L\left(Z^{q *}, T^{*}\right)}{\partial T^{*}} \leq 0 \\
T^{*} \geq 0 \\
T^{*} \frac{\partial L\left(Z^{q *}, T^{*}\right)}{\partial T^{*}}=0 \Longleftrightarrow T^{*}=0 \text { or } \frac{\partial L\left(Z^{q *}, T^{*}\right)}{\partial T^{*}}=0 \\
\frac{\partial L\left(Z^{q *}, T^{*}\right)}{\partial \lambda_{1}^{*}} \geq 0 \\
\frac{\partial L\left(Z^{*}, T^{*}\right)}{\partial \lambda_{2}^{*}} \geq 0 \\
\lambda_{1}^{*} \geq 0 \\
\lambda_{2}^{*} \geq 0 \\
\lambda_{1}^{*} \frac{\partial L\left(Z^{q *}, T^{*}\right)}{\partial \lambda_{1}^{*}}=0 \Longleftrightarrow \lambda_{1}^{*}=0 \text { or } \frac{\partial L\left(Z^{q *}, T^{*}\right)}{\partial \lambda_{1}^{*}}=0 \\
\lambda_{2}^{*} \frac{\partial L\left(Z^{q *}, T^{*}\right)}{\partial \lambda_{2}^{*}}=0 \Longleftrightarrow \lambda_{2}^{*}=0 \text { or } \frac{\partial L\left(Z^{q *}, T^{*}\right)}{\partial \lambda_{2}^{*}}=0
\end{gathered}
$$

According to conditions (17) and (20) there are four cases:

\section{A.1 Case 1: $Z^{q *}>0$ and $T^{*}=0$}

If $Z^{q *}>0$, it implies by (18) that $\frac{\partial L\left(Z^{q *}, T^{*}\right)}{\partial Z^{q *}}=0$ which gives:

$$
\left[(1-\alpha)\left(1-\lambda_{1}^{*}\right)+\lambda_{2}^{*}\right]\left(q_{H} R_{E}^{q}-T^{*}\right)+\lambda_{1}^{*}(1-\alpha)\left(q_{H} R-L\right)=0
$$

If $T^{*}=0$, this equation becomes:

$$
\left[(1-\alpha)\left(1-\lambda_{1}^{*}\right)+\lambda_{2}^{*}\right] q_{H} R_{E}^{q}+\lambda_{1}^{*}(1-\alpha)\left(q_{H} R-L\right)=0
$$

By $(19),\left(1-Z^{q *}\right)\left[(1-\alpha)\left(1-\lambda_{1}^{*}\right)+\lambda_{2}^{*}\right] \leq 0$ but $Z^{q *} \neq 1$ so $(1-\alpha)\left(1-\lambda_{1}^{*}\right)+\lambda_{2}^{*} \leq 0$

If $(1-\alpha)\left(1-\lambda_{1}^{*}\right)+\lambda_{2}^{*}=0$ it implies:

either $q_{H} R-L=0$ but this is not possible because by assumption: $q_{H} R-L \neq 0$,

or $\lambda_{1}^{*}=0$, which implies that $\left[(1-\alpha)+\lambda_{2}^{*}\right] q_{H} R_{E}^{q}=0$ but all terms of this equation are positive or nil, according to $\alpha<1$ and the condition (25). So $\lambda_{1}^{*} \neq 0$ and the investors' participation constraint is binding according to condition (26).

Hence $(1-\alpha)\left(1-\lambda_{1}^{*}\right)+\lambda_{2}^{*} \neq 0$ meaning also that $\lambda_{1}^{*} \neq 1$ and $\lambda_{2}^{*} \neq 0$ so that the no-manipulation constraint is binding, according to condition (27).

So the consistent constraint is $(1-\alpha)\left(1-\lambda_{1}^{*}\right)+\lambda_{2}^{*}<0$ which is equivalent to $(1-\alpha)\left(1-\lambda_{1}^{*}\right)<-\lambda_{2}^{*}$ but the condition (25) must hold, implying: $\lambda_{1}^{*}>1$.

According to (24) and the previous conditions:

$\left[(1-\alpha)\left(1-\lambda_{1}^{*}\right)+\lambda_{2}^{*}\right] q_{H} R_{E}^{q}+\lambda_{1}^{*}(1-\alpha)\left(q_{H} R-L\right)=0$, it induces that $q_{H} R-L>0$.

Thanks to the binding no-manipulation constraint (27), the optimal level of continuation in the case of poor matching is obtained:

$$
Z_{q}^{*}=\frac{Z^{r}\left(q_{H}-\tau\right) R_{E}^{r}}{q_{H} R_{E}^{q}}
$$

Conclusion: When $q_{H} R-L>0$, the couple $\left(Z_{q}^{*}=\frac{Z^{r}\left(q_{H}-\tau\right) R_{E}^{r}}{q_{H} R_{E}^{q}}, T^{*}=0\right)$ is the solution of the program P and both the investors'participation constraint and the no-manipulation constraint are binding. 


\section{A.2 Case 2: $Z^{q *}>0$ and $T^{*}>0$}

If $Z^{q *}>0$, it implies by (18) that $\frac{\partial L\left(Z^{q *}, T^{*}\right)}{\partial Z^{q *}}=0$ which gives:

$$
\left[(1-\alpha)\left(1-\lambda_{1}^{*}\right)+\lambda_{2}^{*}\right]\left(q_{H} R_{E}^{q}-T^{*}\right)+\lambda_{1}^{*}(1-\alpha)\left(q_{H} R-L\right)=0
$$

If $T^{*}>0$, it implies by $(21)$ that $\frac{\partial L\left(Z^{q^{*}}, T^{*}\right)}{\partial T^{*}}=0$ which gives:

$$
(1-\alpha)\left(1-\lambda_{1}^{*}\right)+\lambda_{2}^{*}=0
$$

Either $q_{h} R-L=0$ which is excuded by assumption, or $\lambda_{1}^{*}=0$ which is not possible (see the previous case). So, there is no optimal solution for this program $\mathrm{P}$ with both positive continuation and positive severance pay.

\section{A.3 Case 3: $Z^{q *}=0$ and $T^{*}>0$}

If $Z^{q *}=0$, it implies by (19) that: $(1-\alpha)\left(1-\lambda_{1}^{*}\right)+\lambda_{2}^{*} \leq 0$.

If $T^{*}>0$, it implies by $(21)$ that: $(1-\alpha)\left(1-\lambda_{1}^{*}\right)+\lambda_{2}^{*}=0$.

According to condition (16):

$$
\left[(1-\alpha)\left(1-\lambda_{1}^{*}\right)+\lambda_{2}^{*}\right]\left(q_{H} R_{E}^{q}-T^{*}\right)+\lambda_{1}^{*}(1-\alpha)\left(q_{H} R-L\right) \leq 0
$$

So, $\lambda_{1}^{*}(1-\alpha)\left(q_{H} R-L\right) \leq 0$ but condition (24) must hold, it implies that : $q_{H} R-L<0$.

Given that: $(1-\alpha)\left(1-\lambda_{1}^{*}\right)+\lambda_{2}^{*}=0$ it follows that $(1-\alpha)\left(1-\lambda_{1}^{*}\right)=-\lambda_{2}^{*}$ but the condition (25) must hold, so $\left(\lambda_{1}^{*}, \lambda_{2}^{*}\right)$ must satisfy the conditions: $\lambda_{1}^{*} \geq 1, \lambda_{1}^{*} \neq 0$ and $\lambda_{2}^{*} \geq 0$. The investors'participation constraint is binding whereas the no-manipulation constraint could be binding or not, given that $\lambda_{2}^{*} \geq 0$ which verify the conditions (16) to (27).

Is the optimal solution relaxing at most one of the constraints i.e $\lambda_{2}^{*}=0$ ?

The investors' participation constraint induces a positive relationship between $T^{*}$ and $A$ such that: $\frac{\partial A}{\partial T^{*}}=1-\alpha>0$ indeed $A=I-$ constant $-(1-\alpha)\left(L-T^{*}\right)$ according to the constraint (26). The entrepreneur's utility does not change with $\mathrm{T}: \frac{\partial U_{E}}{\partial T}=0$. The optimal solution is the one which increases the investors' pledgeable income. Suppose that $T>Z^{r}\left(q_{H}-\tau\right) R$, i.e $\lambda_{2}^{*}=0$ rather than $T=Z^{r}\left(q_{H}-\tau\right) R$, i.e $\lambda_{2}^{*}>0$, it implies an increase in $A$ which corresponds to a decrease in the investors' pledgeable income. Bindng the no-manipulation constraint allows us to maximize the investors'pledgeable income.

Conclusion: When $q_{H} R-L<0$, the couple $\left(Z_{q}^{*}=0, T^{*}=Z^{r}\left(q_{H}-\tau\right) R_{E}^{r}\right)$ is an optimal solution of the program $\mathrm{P}$ with both the investors' participation constraint and the no-manipulation constraint which are binding.

\section{A.4 Case 4: $Z^{q *}=0$ and $T^{*}=0$}

If $Z^{q^{*}}=0$, it implies by (19) that: $(1-\alpha)\left(1-\lambda_{1}^{*}\right)+\lambda_{2}^{*} \leq 0$

¿From (16) and $T^{*}=0$ : $\left[(1-\alpha)\left(1-\lambda_{1}^{*}\right)+\lambda_{2}^{*}\right] q_{H} R_{E}^{q}+\lambda_{1}^{*}(1-\alpha)\left(q_{H} R-L\right) \leq 0$

If $(1-\alpha)\left(1-\lambda_{1}^{*}\right)+\lambda_{2}^{*}=0$ this condition implies $\left(q_{H} R-L\right)<0$. If $\lambda_{2}^{*} \neq 0$ then the no-manipulation constraint is binding but the solution is not optimal: $Z^{r}\left(q_{H}-\tau\right) R_{E}^{r}=0$. If the no-manipulation constraint is not binding the solution is not optimal for the same reason as in the previous case 3. There are no optimal solutions with both no continuation and no severance pay provision. 


\section{B Appendix 2}

For entirely taxable private benefits: An optimization under linear inequality constraints is performed, see Appendix 1, in order to solve this program, with Lagrangean denoted $L\left(Z^{q}, T\right)$ with $\lambda_{1}$ and $\lambda_{2}$ the Lagrangean multipliers respectively of the first and second constraint.

$$
\begin{gathered}
\frac{\partial L\left(Z^{q *}, T^{*}\right)}{\mathrm{dZ^{q* }}}=q_{H} R_{E}^{q}\left[(1-\alpha)\left(1-t-\lambda_{1}^{*}\right)+\lambda_{2}^{*}(1-t)\right]-T^{*}\left[(1-\alpha)\left(1-t_{T}-\lambda_{1}^{*}\right)+\lambda_{2}^{*}\left(1-t_{T}\right)\right]+(1-\alpha) \lambda_{1}^{*}\left(q_{H} R-L\right) \\
\frac{\partial L\left(Z^{q *}, T^{*}\right)}{\mathrm{dT}^{*}}=\left(1-Z^{q *}\right)\left[(1-\alpha)\left(1-t_{T}-\lambda_{1}^{*}\right)+\lambda_{2}^{*}\left(1-t_{T}\right)\right]
\end{gathered}
$$

The two relevant cases are the symmetric cases already obtained for the optimal contract but regimes are not the same according to the comparison of the two taxes.

Case 1: The continuation-type contract:

The optimal contract is such that: $Z^{q^{*}}>0$ and $T^{*}=0$

we obtain: $\frac{\partial L\left(Z^{q *}, T^{*}\right)}{\mathrm{dZ}^{q *}}=0$ which implies : $\lambda_{1}^{*}=\frac{q_{H} R_{E}^{q}(1-t)\left(1-\alpha+\lambda_{2}^{*}\right)}{(1-\alpha)\left[q_{H} R_{E}^{q}-\left(q_{H} R-L\right)\right]}$ and from $(29)$ and $\frac{\partial L\left(Z^{q *}, T^{*}\right)}{\mathrm{dT}^{*}} \leqslant$ 0 , the following condition is obtained:

$$
-\left[\frac{q_{H} R_{E}^{q}\left(t_{T}-t\right)}{\left(1-t_{T}\right)}\right] \leqslant q_{H} R-L
$$

We denoted $K_{1}\left(t, t_{T}\right)=\frac{q_{H} R_{E}^{q}\left(t_{T}-t\right)}{\left(1-t_{T}\right)}$, its sign depends on the comparison between the two taxes.

If $t_{T}=t$ then $K_{1}\left(t, t_{T}\right)=0$ so $0 \leqslant q_{H} R-L$

If $t_{T}<t$ then $K_{1}\left(t, t_{T}\right)<0$ so $0<-K_{1}\left(t, t_{T}\right) \leqslant q_{H} R-L$

If $t_{T}>t$ then $K_{1}\left(t, t_{T}\right)>0$ so $-K_{1}\left(t, t_{T}\right) \leqslant q_{H} R-L$

The optimal contract is the continuation-type, which is the same as in the case without taxes:

$$
Z^{q *}\left(t, t_{T}\right)=\frac{Z^{r}\left(q_{H}-\tau\right) R_{E}^{r}}{q_{H} R_{E}^{q}}
$$

Case 2: The parachute-type contract:

The optimal contract is such that: $Z^{q *}=0$ and $T^{*}>0$

which gives : $\frac{\partial L\left(Z^{q *}, T^{*}\right)}{\mathrm{dZ}^{q *}} \leqslant 0$ and $\frac{\partial L\left(Z^{q *}, T^{*}\right)}{\mathrm{dZ}^{q *}}=0$ we obtain:

$$
\frac{q_{H} R_{E}^{q}\left(t_{T}-t\right)}{\left(1-t_{T}\right)} \leqslant-\left(q_{H} R-L\right)
$$

If $t_{T}=t$ then $K_{1}\left(t, t_{T}\right)=0$ so $q_{H} R-L \leqslant 0$

If $t_{T}<t$ then $K_{1}\left(t, t_{T}\right)<0$ so $q_{H} R-L \leqslant-K_{1}\left(t, t_{T}\right)$

If $t_{T}>t$ then $K_{1}\left(t, t_{T}\right)>0$ and $q_{H} R-L \leqslant-K_{1}\left(t, t_{T}\right)$.

The optimal contract is a parachute-type which is different from the case without taxes:

$$
T^{*}\left(t, t_{T}\right)=\frac{Z^{r}\left(q_{H}-\tau\right) R_{E}^{r}(1-t)}{\left(1-t_{T}\right)}
$$

\section{Appendix 3}

For entirely taxable private benefits: If $Z_{c}^{q *}>0$ and $T_{c}=0$, it implies:

$$
\left[(1-\alpha)\left(\gamma-\lambda_{1}^{*}\right)+\lambda_{2}^{*}\right] q_{H} R_{E}^{q}+\lambda_{1}^{*}(1-\alpha) \gamma\left(q_{H} R-L\right)=0
$$


By the same steps as in the Appendix 1: $\left[(1-\alpha)\left(\gamma-\lambda_{1}^{*}\right)+\lambda_{2}^{*}\right] q_{H} R_{E}^{q}+\lambda_{1}^{*}(1-\alpha) \gamma\left(q_{H} R-L\right)=0$, it implies that $q_{H} R-L>0$. Thanks to the binding no-manipulation constraint (27), the optimal level of continuation in the case of poor matching is obtained:

$$
Z_{c}^{q *}=\frac{Z^{r}\left(q_{H}-\tau\right) R_{E}^{r}}{q_{H} R_{E}^{q}}
$$

There are no changes in the solutions form for the other cases.

\section{REFERENCES}

ATANASSOV and HAN KIM , [2008], "Labor and Corporate Governance: International Evidence from Restructuring Decisions ", Journal of Finance, Forthcoming.

BEBCHUK L., JOLLS C., [1999], "Managerial Value Diversion and Shareholder Wealth", Journal of Law, Economics and Organisation, Isuue 2, pp. 487-502.

CHOE C., [1998], "A mechanism design approach to an optimal contract under ex ante and ex post private information ", Review of Economic Design, Vol 3, pp. 237-255.

DECHOW, HUTTON and SLOAN , [1996], "Causes and Consequences of Earnings Manipulations: An Analysis of Firms subject to enforcement Actions by the SEC. ",Contemporary Accounting Research, Vol 13, No 2 .

DYCK A., ZINGALES L., [2004], "Private Benefits of Control: An International Comparison", Vol 59, Issue 2, pp. 537-600

GOERKE L. and PANNENBERG JC., [2009], "The effects of income taxation on severance pay", Labour Economics, Vol 16, pp 107-118

HAUTCOEUR P-C., [1999] "Asymétries d'information, coûts de mandat et financement des entreprises françaises (1890-1936)", Revue Economique, Vol 5, pp. 1053-1087

INDERST R. and MUELLER H., [2008], "CEO replacement under Private Information", Working paper NYU

KARLSSON P.O., NEILSON G.L. and WEBSTER J.C. , [2008], "CEO succession2007: The performance paradox. ",Strategy+Business, issue 51, summer.

KNOEBER C R. , [1986], "Golden Parachutes, Shark Repellents, and Hostile Tender Offers ",American Economic Review, Vol 76, No 1, pp. 155-67.

LA PORTA R., LOPEZ-DE-SILANES F., SHLEIFER A., VISHNY R., [2000], "Investor Protection and Corporate Governance", Journal of Financial Economics, Vol 58, pp. 3-27.

PAGANO M. and VOLPIN P., [2005], "Managers, Workers and Corporate Control", The Journal of Finance, Vol 60, Issue 2, pp. 841-868.

PHILIPPON T. and KEDIA S. , [2006], "The Economics of Fraudulent Accounting" forthcoming in Review of Financial Studies

SHLEIFER A. and SUMMERS L., [1989], "Breach of trust in hostile takeovers", NBER Chapters, in: Corporate Takeovers: Causes and Consequences, pp. 33-68

SUBRAMANIAN N. CHAKRABORTY A. and SHEIKH S., [2002], "Performances incentives, performances pressure and executive turnover ",Econ WPA Finance.

TIROLE J., [2006], "The Theory of Corporate finance ",Princeton university Press. 